\title{
O entendimento do conceito de gestão democrática na escola pública: caso específico do Estado da Bahia (Brasil)
}

\author{
Understanding the concept of democratic management in public \\ schools: a specific case of the state of Bahia (Brazil)
}

\section{Sônia Fonseca ${ }^{1}$ \\ Héctor Monarca² \\ Cristiane Nunes ${ }^{3}$}

\section{Resumo}

Este artigo objetiva refletir sobre o Art. 206 da Constituição Brasileira de 1988 e seu entendimento pelo(a)s diretores(as) das escolas públicas do Ensino Médio, no Estado da Bahia. Trata-se de um recorte preliminar da pesquisa, Gestão da Escola e os Resultados do $\mathrm{IDEB}^{4}$ : qual a relação? A abordagem teórica baseou-se nos estudos de Luck (1996), Paro (2000), Ravitch (2011) e Monarca (2018a). Metodologicamente o estudo é exploratório descritivo, incidindo nos resultados obtidos com uma amostra de 126 sujeitos, diretores de escolas, respondentes ao questionário. 0 resultado principal identifica que há um entendimento polissêmico,

\footnotetext{
1 Doutora em Educação, docente do Programa de Pós-Graduação em Educação (PPGE) e do Departamento de Ciências Administrativas e Contábeis (DCAC), Universidade Estadual de Santa Cruz (UESC) - Ilhéus-Bahia-Brasil; Coordenadora do Grupo de Pesquisa em Educação e Gestão (GPEG). Email: soniafonseca19@gmail.com

${ }^{2}$ Doutor em Educação. Universidade Autónoma de Madrid. Grupo de Investigación sobre Políticas Educativas Supranacionales (GIPES). Email: hector.monarca@uam.es

${ }^{3}$ Doutora em Educação; Professora da; Assessora da Diretoria Superintendência do SEBRAE-SE. Email: profacristavares@outlook.com

${ }^{4}$ Índice de Desenvolvimento da Escola Básica.
} 
pelo(a)s diretores(as), sobre o conceito de "gestão democrática" e padrão de qualidade, diferindo do que preceitua os incisos analisados.

Palavras-Chave: Gestão; qualidade; neoliberalismo.

\section{Abstract}

This article aims to reflect on Article 206 of the Brazilian Constitution of 1988 and its understanding by the principals of public high schools in the State of Bahia. This is a preliminary cut of the research, "School Management and the IDEB Results: what is the relationship?". The theoretical approach was based on the studies of Luck (1996), Paro (2000), Ravitch (2011) and Monarca (2018a). Methodologically the study is descriptive exploratory, focusing on the results obtained with a sample of 126 subjects, school principals, respondents to the questionnaire. The main result identifies that there is a polysemic understanding, by the directors, about the concept of "democratic management" and quality standard, differing from the precepts analyzed.

Keywords: Management; quality; neoliberalism.

\section{Introdução}

A Constituição Brasileira de 1988 é considerada como a "Constituição Cidadã" por priorizar a defesa aos direitos sociais e à dignidade humana. Ela traz inovações e responsabilidades para o Estado em vários aspectos e, no âmbito da educação, privilegia princípios nunca apontados em Constituições anteriores. 0 Art. 206 é um exemplo. Ele determina que o ensino será ministrado com base nos seguintes princípios (Brasil, 1988): "[...] VI-gestão democrática do ensino público, na forma da lei; VII-garantia de padrão de qualidade [...]".

Desse modo, este artigo será subdividido em três partes, a saber: a primeira, uma síntese sobre o contexto geral da Promulgação da Constituição Brasileira, enfocando os reflexos do Neoliberalismo na educação e as contradições de entendimento sobre o Art. 206, incisos VI e VII da referida Constituição. A segunda, relata-se a polissemia existente com o conceito de "gestão democrática" 
e a terceira, um recorte dos resultados de um projeto de pesquisa, «gestão da escola e os resultados do IDEB $^{5}$ : qual a relação?» Desse projeto, utilizamos o perfil do(a) diretor(a) da escola e seu entendimento sobre o conceito de "gestão democrática" aplicado no cotidiano escolar.

Nesse sentido, nossa questão de pesquisa é: Qual o entendimento dos diretores sobre o conceito de "gestão democrática" e se ele oferece alguma contribuição para o padrão de qualidade das escolas?

Após a promulgação da Constituição, a Lei de Diretrizes e Bases da Educação (LDB), Lei n.o 9.394 de 23 de Dezembro de 1996, em harmonização com a Constituição, estabeleceu em seu Art. $9^{\circ}$ que a União incumbir-se-á de elaborar o Plano Nacional de Educação (PNE), em colaboração com os Estados, o Distrito Federal e os Municípios. O PNE é um documento que norteia a educação brasileira, com validade de 10 anos, e seu objetivo principal é o de estabelecer metas que a melhore. A Lei que aprova o PNE estabelece em seu Art. $2^{\circ}$ que Estados, Distrito Federal e Municípios devem, com base no Plano Nacional, também elaborar os seus Planos decenais respectivamente (Brasil, Lei n. ${ }^{\circ}$ 10.172/2001).

Assim, o primeiro PNE com validade até 2010 tinha como centralidade a universalização da Educação Básica e a democratização da gestão da educação em todos os níveis. Além disso, definia, também, na Meta 22 que cada sistema de ensino deveria desenvolver "normas de gestão democrática do ensino público, com a participação da comunidade".

O segundo PNE com duração de 2011 a 2020 ratifica a universalização do Ensino Médio como também a melhora da qualidade do ensino, de modo que ele obtivesse média 5,2 no IDEB até o ano de 2021. Com relação à "gestão democrática", a única indicação é a Meta 19: "Garantir, mediante lei específica aprovada no âmbito dos Estados, do Distrito Federal e dos Municípios, a

\footnotetext{
${ }^{5}$ O IDEB Foi criado em 2007, pelo Instituto Nacional de Estudos e Pesquisas Educacionais Anísio Teixeira (Inep), formulado para medir a qualidade do aprendizado nacional e estabelecer metas para a melhoria do ensino. Funciona como um indicador nacional que possibilita o monitoramento da qualidade da Educação. Recuperado em 03 junho, 2019, de https://bit.ly/203IkU3
} 
nomeação comissionada de diretores de escola vinculada a critérios técnicos de mérito e desempenho e à participação da comunidade escolar".

Permeado pelas ideias neoliberais na elaboração desses PNEs, o modelo de gestão da Educação Básica sofre também com a instabilidade política que perpassa o Brasil durante esses últimos 30 anos. Nessa direção, temos como hipótese que há um equívoco entre os preceitos das leis, o conceito de gestão e de sua prática na escola e o lugar da qualidade nesse emaranhado desconectado de leis.

Desse modo, para entendermos o contexto em que se deu a Promulgação da Constituição Brasileira, na seção seguinte, faremos um breve relato do panorama político da época.

\section{O Contexto Geral da Promulgação da Constituição Brasileira e o Enfoque sobre os Reflexos do Neoliberalismo na Gestão da Escola Pública}

A sociedade brasileira viveu, de 1964 a 1985, a experiência de sucessivas crises de ordem política, econômica e social. Momentos em que o Estado retirou do cidadão as garantias individuais, pública e privada, afetando fortemente o setor educacional, não apenas pela repressão ao livre arbítrio, mas pela priorização da educação tecnicista que atendesse à industrialização advinda do capital estrangeiro. A modernidade educacional anunciada pelo período da Ditadura Militar era, segundo Aranha (1996), baseada nos três pilares ideológicos: educação e desenvolvimento; educação e segurança; educação e comunidade justificada pelos conceitos de racionalidade, de eficiência e de produtividade utilizados no setor industrial.

A década de 1980 ficou definida entre o conservadorismo do Estado patrimonial, as necessidades de ideais de redemocratização e a eficiência na gestão do Estado brasileiro que dar-se-ia por meio de uma grande reforma que, segundo Bresser Pereira (1999, p. 12), compreende três dimensões: a) institucional-legal, voltada à desburocratização e descentralização da estrutura do Estado; b) gestão, guiada pela autonomia e novas formas de responsabilização dos gestores em que deveriam promover resultados e, por último, c) cultural em 
que todo esforço dar-se-ia para que houvesse mudança de mentalidade no serviço público, eliminando a cultura da desconfiança da administração patrimonialista e burocrática para a confiança, o alto desempenho e o cumprimento de metas, próprios da administração gerencial.

É nesse contexto que emerge a Constituição de 1988, com o propósito de recuperar os direitos retirados da sociedade; substituir as características da educação autoritária, "bancária", por uma educação "libertadora" Freire (1996), que conscientizasse o educando à autonomia transformado pela educação em um ser que intervém no mundo. Para Freire (1996, p. 78):

[...] não há nem jamais houve prática educativa em espaço-tempo nenhum de tal maneira neutra, comprometida apenas com ideias preponderantemente abstratas e intocáveis. Insistir nisso e convencer ou tentar convencer os incautos que essa é a verdade é uma prática política indiscutível com que se pretende amaciar a possível rebeldia dos injustiçados.

A educação da autonomia proposta por Freire sustentava-se no diálogo e na ação. $O$ diálogo como prática pedagógica em que o docente interage com o estudante, problematizando situações de modo que ele aprenda a aprender e essa prática dar-se-á por meio de um conteúdo programático vinculado ao cotidiano do estudante dele caracterizado por Paulo Freire como ação.

O período de 1985 a 1990 foi marcado por idas e vindas no aspecto econômico brasileiro. Muitos pacotes econômicos de curtos êxitos continuavam arrastando o país para um ciclo econômico frágil e inercial ${ }^{6}$. Um dos planos, o Plano Cruzado, trazia como ação prioritária: o congelamento de preços, substituição de moeda, gatilho salarial (aumento dos salários toda vez que a inflação atingisse $20 \%$ ao mês), mas ela alcançou patamares insuportáveis, em 1981 saltou de $211 \%$ para $235 \%$, e os brasileiros sofriam com o desemprego e seu poder de compra, como bem define Ometto, Furtuoso e Silva (1995, p. 404):

As raízes dessa crise, que se manifesta inicialmente como uma crise de endividamento externo, mas que rapidamente passa a se traduzir no

\footnotetext{
${ }^{6}$ Economia caracterizada por uma inflação de taxas elevadas com tendência a hiperinflação, em que os preços passam a crescer de forma explosiva, causando desequilíbrio na macroeconomia.
} 
desajuste interno da economia, estão nas políticas adotadas na década anterior, quando a opção pela manutenção do crescimento econômico após o primeiro choque do petróleo, e, mais do que isso, a busca do salto definitivo no aprofundamento do processo de substituição de importações, levaram o Estado brasileiro a assumir um padrão de financiamento baseado no crescente endividamento externo.

Essa configuração econômica da década de 1980 é considerada, por alguns cientistas sociais, como a "década perdida" e tem seus reflexos na educação, já que esse foi o setor mais sensível no período da Ditadura Militar.

Entretanto, apesar de toda a instabilidade e a repressão dessa década, com políticas educacionais ainda atreladas ao autoritarismo, alguns movimentos a favor da redemocratização como a Associação Nacional de Educação (ANDE), o Centro de Estudos Educação e Sociedade (CEDES) e a Associação Nacional de Pesquisa e PósGraduação em Educação (ANPED), fomentavam ações, que reivindicavam o banimento da educação tecnicista adaptada à concepção taylorista em que o planejamento e a organização racional do trabalho na escola eram sinônimos de eficiência.

É nesse clima de participação popular que essas organizações influenciaram a elaboração da Lei de Diretrizes e Bases da Educação, conclamando políticas públicas de inclusão e ações que reduzissem a evasão e a repetência nos Ensinos Fundamental e Médio, além da autonomia da gestão da educação.

O final dessa década contribuiu para estruturar e formular leis que se pensavam trazer fortes contribuições para a consolidação da educação como setor que alteraria o grau de importância do Brasil no cenário interno e internacional.

O ano de 1990 se iniciou com a posse do primeiro presidente da República, eleito pelo voto direto, e a consequente esperança que a democracia poderia trazer melhores dias para educação em razão das promessas de campanha do novo governo, que eram adotar a prática da equidade econômica e social no país pelo caminho da educação.

Entretanto, nesse período, dá-se o marco das políticas neoliberais no Brasil, corroboradas pelo movimento da globalização e com receitas já conhecidas: privatizações, mínima intervenção do Estado no mercado de trabalho e de 
capitais, eliminação do protecionismo econômico, aumento de tributos etc., como bem afirma Harvey (2008, p. 13):

[...] o neoliberalismo é em primeiro lugar uma teoria de práticas econômicopolíticas que propõe que o bem-estar humano pode ser promovido liberandose as liberdades e capacidades empreendedoras individuais no âmbito de uma estrutura institucional caracterizada por sólidos direitos a propriedade privada, livres mercados e livre comércio. 0 papel do Estado é criar e preservar uma estrutura institucional apropriada a essas práticas.

E assim, sob essa ótica, as funções básicas do Estado como responsáveis pela Alocação, Distribuição e Estabilização dos fatores de produção, no Neoliberalismo são substituídas pelo Estado mínimo, em que a iniciativa privada ${ }^{7}$ passa a ocupar importante papel nas atividades de ganho a curto prazo. Entretanto, os serviços que estão nos Princípios Constitucionais como dever de o Estado cumpri-los, protegendo as minorias pela equidade, por meio de políticas públicas, por exemplo, para a educação, o Estado não terceirizou em sua totalidade nem demonstrou eficiência nos serviços prestados.

No âmbito da educação, entre 1990 e 2000, o Neoliberalismo "esqueceu" de sua responsabilização na função distributiva e estabilizadora na área da educação e em nome da qualidade, da inovação, da competitividade e da produtividade, retirou a educação do campo social e político, deixando a mercê das regras do mercado. As Universidades brasileiras foram, propositalmente, sucateadas para estimular a participação de uma fatia maior do mercado à iniciativa privada.

Especificamente, a partir de 2002 até 2010, houve modificações no direcionamento das funções do Estado brasileiro. As políticas públicas estavam voltadas à democratização do ensino, redução da taxa de analfabetismo, universalização do Ensino Fundamental, a descentralização de programas compartilhados com Estados, Municípios e as próprias escolas, na busca de melhorar a efetividade dos programas federais, como, por exemplo, o Programa Dinheiro Direto na Escola (PDDE), que é o repasse direto de recursos financeiros

\footnotetext{
7 Para expandir a discussão sobre privatização ver Fernández-González (2019).
} 
para a escola, conforme explicação do site do Fundo Nacional de Desenvolvimento da Educação (s/n):

O Programa Dinheiro Direto na Escola (PDDE) tem por finalidade prestar assistência financeira para as escolas, em caráter suplementar, a fim de contribuir para manutenção e melhoria da infraestrutura física e pedagógica, com consequente elevação do desempenho escolar. Também visa fortalecer a participação social e a autogestão escolar.

Esse é o típico Programa de Política Pública que representa a dissociação entre medidas de gabinete e suas execuções nas realidades locais que impactam diretamente na eficiência da escola, além de iniciar um processo em que possibilita ao(à) diretor(a) da escola cindir com a gestão prescritiva taylorista para uma gestão democrática, inovadora e eficiente.

Desde a Promulgação da Constituição Brasileira até os nossos dias, nenhuma lei regulamentou o Art. 206, no tocante ao inciso VI de modo a elucidálo. Ao contrário, deixa margem a uma série de entendimentos utilizados por alguns autores, como: Luck (1996), Libânio (2007), Hora (2006), Paro (2007), Lima (2014), dentre outros, que entendem a "gestão democrática" como a forma de escolha democrática do corpo diretivo da escola feita pela participação e controle social. Como afirma Paro (2007, p. 23):

Toda vez que se propõe uma gestão democrática da escola pública de $1^{\circ} \mathrm{e}$ $2^{\circ}$ graus que tenha efetiva participação de pais, educadores, alunos e funcionários da escola, isso acaba sendo considerado como coisa utópica [...] A palavra utopia significa lugar que não existe. Não quer dizer que não possa vir a existir.

Realmente, poderá vir a existir, a partir do momento em que a sociedade seja, intencionalmente, educada para tomar decisões que visem o bem comum, o bem público.

Como podemos observar nas palavras de Paro (2007, p. 11) "temos hoje um sistema hierárquico que, pretensamente, coloca todo o poder nas mãos do diretor como autoridade única". Observe que a preocupação do autor é com a estrutura de poder centrado nas mãos de uma única pessoa. Não se refere aqui, nem em 
nenhuma das Leis do Estado (Constituição, LDB e PNE), ao corpo diretivo, ou seja, estamos sempre tentando resolver problemas novos com soluções antigas.

Embora não discordemos integralmente desses autores sobre o conceito de "gestão democrática", nosso entendimento sobre o inciso VI do Art. 206 da Constituição é que se refere apenas a "escolha" democrática do(a) diretor(a) da escola. O modelo ou a forma em que as gestões pedagógica e administrativa são feitas no cotidiano da escola continuam sendo baseadas na concepção taylorista.

Em nossos estudos e experiência no Ensino Superior, um modelo que poderia sustentar bem e quebrar a prerrogativa única do poder do(a) diretor(a) poderia ser aquele em que a escola sustentar-se-ia no seguinte tripé: 1) um corpo diretivo eleito democraticamente, descentralizando, assim, o papel do diretor; 2) um conselho consultivo, também eleito, com a participação da comunidade educativa; 3) conselho de monitoramento. Este último, composto por pessoas com conhecimentos específicos em currículo e avaliação, podendo ser inclusive, pessoas externas a escola.

É óbvio que estamos nos referindo a um modelo em que as pessoas tenham capacitação, motivação, responsabilidade e pensem no bem coletivo, ou seja, um modelo democrático em que toda a comunidade escolar passe a decidir, participativamente, no destino da escola, planejando, organizando, liderando e efetuando os monitoramentos respectivos.

Timidamente, a escolha democrática do(a) diretor(a) da escola vem acontecendo no Brasil. O Gráfico 1, a seguir, mostra que a adesão dos Estados e Municípios ainda é pequena. A forma de indicação do(a) diretor(a) antes era apenas política, hoje, somente $21 \%$ dos Estados escolhem seus diretores pelo instrumento da eleição. 


\section{Gráfico 1. Percentual de escolas para ocupação do cargo de direção escolar}

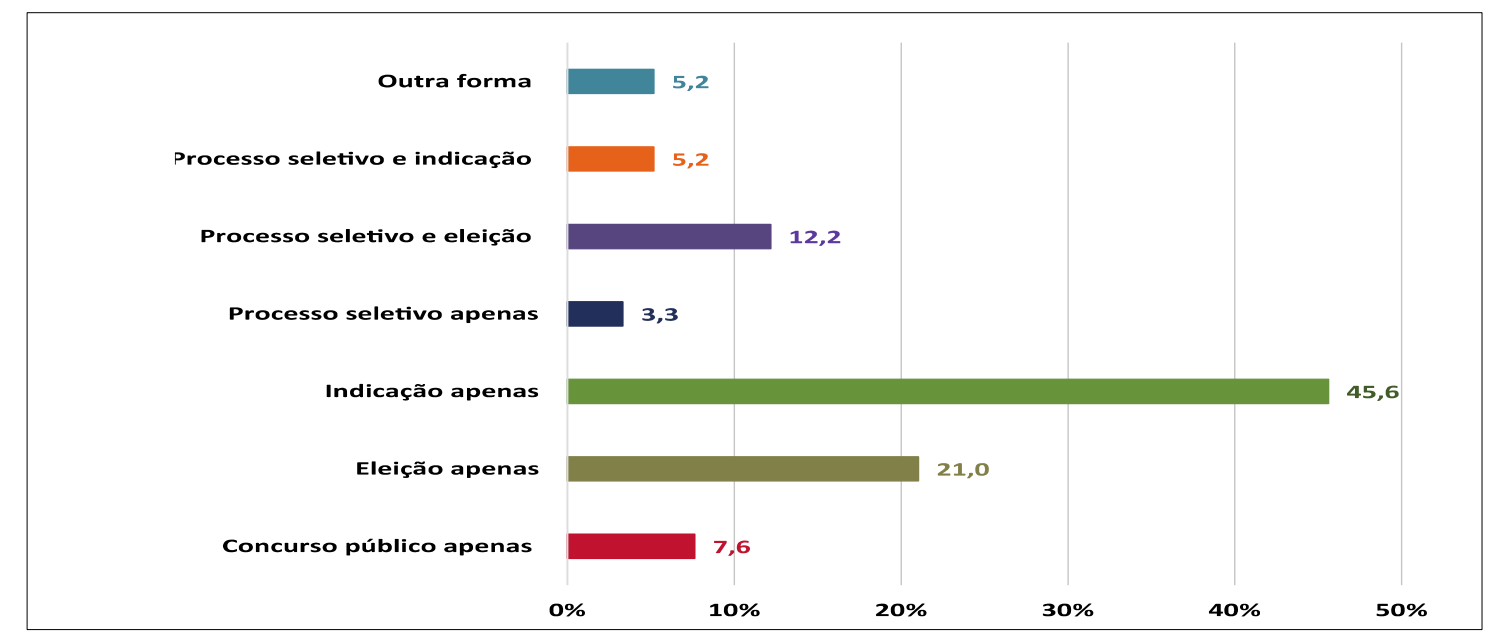

Fonte: INEP/MEC, ciclo de monitoramento das metas do PNE, 2016, p.420.

O gráfico ainda mostra que, apesar de 30 anos da Constituição brasileira, ainda há mais de $45 \%$ das escolas com diretores(as) sendo escolhidos(as) por indicação. Tal constatação é mais uma indicação de que o Brasil ainda carece de utilizar-se de mecanismos de escolha democrática para suas instituições educacionais.

\subsection{0 padrão de qualidade}

O inciso "VII - garantia de padrão de qualidade" - foi criado para estabelecer que padrão as escolas deveriam ter, entretanto a lei não define o que é padrão de qualidade. Esclarecemos que não nos ateremos a discussão conceitual sobre qualidade em uma política neoliberal de mercado, mas sim dos elementos gerais que constituem um padrão de qualidade no Ensino Médio brasileiro, já que concordamos com Fernández-González e Monarca (2018, p. 12) ${ }^{8}$ quando diz: "Embora entendamos que qualidade tem sido um guarda-chuva para introduzir a lógica neoliberal em educação, não podemos sair por aí dizendo abaixo a qualidade!, porque quem não quer uma educação de qualidade?"

É importante salientar que a meta para se atingir um ensino de qualidade não depende apenas de boas intenções de documentos em forma de lei, por exemplo, o PNE (2001-2010):

8 Tradução nossa. 
Meta 3. Melhorar o aproveitamento dos alunos do ensino médio, de forma a atingir níveis satisfatórios de desempenho definidos e avaliados pelo Sistema Nacional de Avaliação da Educação Básica (Saeb), pelo Exame Nacional do Ensino Médio (Enem) e pelos sistemas de avaliação que venham a ser implantados nos Estados.

Meta 9. Assegurar que, em cinco anos, todas as escolas estejam equipadas, pelos menos com biblioteca, telefone e reprodutor de textos.

Esse conjunto citado faz parte dos itens indispensáveis à qualidade da educação, visto que os equipamentos didáticos auxiliam nos estímulos e na motivação para aprender. Fazemos referência a metas que foram determinadas no decênio 2001 a 2010. Quase 20 anos depois desse primeiro documento (PNE), encontramos nas escolas visitadas, bibliotecas como depósitos de livros empilhados, com exemplares apenas do Programa Nacional do Livro Didático (PNLD) ${ }^{9}$ o que proporciona a formação do estudante com um único viés ideológico sob a ótica do governo.

É comum entendermos o termo "qualidade" como: modo de uma pessoa ser ou fazer que a distingue de outras; busca da melhoria contínua; grau de excelência. Segundo Monarca (2018b, p. 7) ${ }^{10}$, qualidade significa:

É um discurso de poder que conseguiu atrair setores e diversos atores que conseguiram convergir em um mesmo campo, em um mesmo sistema de referências: "acadêmicas", especialistas, investigadores, professores, mãespais, estudantes e cidadãos em geral. Todos falam da qualidade, embora com sentidos diversos e sempre com posições de poder diferenciados.

Ainda segundo Monarca (2018b, p. 7), alguns dos limites da qualidade podem ser entendidos como um "sistema simbólico" em educação, ou seja, não se entende qualidade como um conceito geral para todo um sistema quando as realidades, dentro do mesmo sistema, são diferentes. Mesmo na reforma educacional americana dos anos 90 , Ravitch (2011, p. 12) concluiu que

\footnotetext{
${ }^{9}$ Esse é destinado a avaliar e a disponibilizar obras didáticas, pedagógicas e literárias, entre outros materiais de apoio à prática educativa, de forma sistemática, regular e gratuita, às escolas públicas de Educação Básica das redes federal, estadual, municipal e distrital e, também, às instituições de Educação Infantil comunitárias, confessionais ou filantrópicas sem fins lucrativos e conveniadas com o Poder Público. Recuperado em 04 junho, 2019, de https://bit.ly/2uifKaA

10 Tradução nossa.
} 
[...] os mecanismos de premiação com adicionais nos salários aos professores pelo bom desempenho dos alunos em testes levaram os professores a desenvolverem formas de burlar os resultados, fragilizando o sistema. Os professores passaram a investir no ensino de truques necessários para os alunos responderem à testagem com êxito, em detrimento de uma formação consistente em todas as áreas do conhecimento.

O pensamento de que a solução na gestão das escolas estaria no mercado são analogias apenas para quem tem precário conhecimento do que é educação. Outro ponto ao se discutir qualidade em educação sob a ótica de governos preocupados, prioritariamente, com os parâmetros da Organização de Cooperação e de Desenvolvimento Econômico (OCDE), ou mesmo com o IDEB $^{11}$, temos que concordar com Fernández-González e Monarca (2018, p. 17):

Em suma, quando pensamos na relação entre 'qualidade' e neoliberalismo, pensamos fundamentalmente em dois tipos de tecnologia de governo. De um lado, tecnologias de produção de conhecimento que guiam a política educativa: estatísticas, comparações, governo por meio dos números, política baseada em evidências [...] De outro lado, tecnologias de governo que regulam a lógica escolar dos centros introduzindo uma governabilidade neoliberal (Foucault, 2007), quer dizer, princípios de competitividade entre sujeitos e entre escolas e de responsabilização individual: avaliações externas, liberdade de eleição de escola, incentivos por resultados, lógicas de autonomia controlada ou organização gerencial de centros ${ }^{12}$.

O fato é que mesmo o IDEB, a partir de 2007, ter apresentado indicadores abaixo da meta, no caso do Estado da Bahia, não houve ações governamentais significativas que pudessem melhorar o desempenho das escolas e,

${ }^{11}$ É um indicador que monitora o desempenho da educação nacional, criado em 2007 e está ancorado nos resultados de dois conceitos: 1) o indicador de fluxo escolar baseado nas taxas de aprovação, repetência e evasão, retirados do Censo Escolar; e, 2) desempenho de proficiência em Português e Matemática dos estudantes. Nesse caso, os estudantes do $3^{\circ}$ ano do Ensino Médio participam de uma prova nacional, aplicada pelo Inep por meio do Sistema de Avaliação da Educação Básica (SAEB).

12 Tradução nossa. 
consequentemente, dos alunos. O que é considerado como qualidade da educação serviu apenas para alargar a base da pirâmide do analfabetismo funcional ${ }^{13}$.

Assim, na seção seguinte, pormenorizaremos as ações das políticas públicas voltadas à educação para que se atinja os incisos VI e VII da Constituição e seus reflexos na formação do corpo diretivo como instrumento de estratégia para melhorar a educação.

\section{A Polissemia do Conceito de "Gestão Democrática"}

Nesta seção, discutiremos a importância do corpo diretivo da escola, as políticas públicas para a sua formação e sua relação com os resultados do IDEB. Em qualquer organização, se faz necessário um conjunto adequado de recursos para conseguir os fins a que se propõe. Para tanto, precisa de um corpo diretivo que planeje, coordene, lidere e monitore seus processos. Com a escola não é diferente, o corpo diretivo é responsável pelo atingimento dos resultados, cumprindo objetivos, metas e fins da educação. Segundo Fonseca (2017, p. 642):

[...] a eficiência dos serviços de qualquer organização está, então, vinculada à qualidade da Gestão. O Gestor, independente da área da organização, é responsável por fazer acontecer. Ele é o maestro e deve reger a orquestra de modo a propiciar aos ouvintes a melhor audição.

O corpo diretivo ou a administração de qualquer organização requer competências e habilidades imprescindíveis na gestão, como, por exemplo: liderança formativa, relacionamento interpessoal, empatia, visão do todo, multiculturalismo etc., bem como saber trabalhar com a equipe, o Planejamento, a Organização, a Liderança e a Monitorização.

O tripé de sustentação teórico-conceitual da educação brasileira é constituído pelos: 1) documentos governamentais (Leis, Decretos, Planos etc.); 2) resultados de pesquisa dos cientistas sociais; e, 3) agentes locais (diretores/as) no cotidiano da escola, dão significados diversos para as mesmas coisas, ajustandoos a suas realidades.

\footnotetext{
${ }^{13}$ É a incapacidade demonstrada pelo estudante em não compreender textos compatíveis com sua idade e série.
} 
A escola é um ambiente em que temos pessoas, estrutura e processos e liderar esse conjunto, planejando, organizando e monitorando seus resultados, parece ser atribuição para um(a) super homem/mulher caso não fosse a ciência da Administração, sistematizando o conhecimento e os processos que possibilitam ao corpo diretivo ferramentas para uma gestão com bom desempenho, atendendo aos interesses e às expectativas da comunidade escolar. Para tanto, se faz necessário políticas públicas de capacitação para o corpo diretivo.

Estudos de Kruger, 2003, Hendriks e Steen, 2012, Fonseca, 2018, dentre outros, apontam que o corpo diretivo da escola exerce influência sobre a aprendizagem dos estudantes, permitindo ações na dinâmica do cotidiano da escola em que sua liderança promove um processo de sinergia com professores, estudantes, famílias e sociedade em geral. Na linguagem da gestão, atua aglutinando os stakholderes ${ }^{14}$ da escola em razão de um único objetivo, o desenvolvimento dos estudantes.

Um estudo realizado pelos pesquisadores Murillo e Martínez-Garrido (2015) aponta que, no Brasil, 45,42\% dos diretores da escola básica urbana não têm formação permanente. Do estudo, extraímos os dados, a seguir, para exemplificar a configuração em que o país se encontra.

\section{Quadro 1. Porcentagem de diretores(as) sem formação especializada e com mais de $\mathbf{2 0 0}$ horas de formação permanente em escolas públicas urbanas e rurais, em cada país}

\begin{tabular}{|l|c|c|c|c|}
\hline \multirow{2}{*}{ País } & \multicolumn{2}{|c|}{ Sem Formação (\%) } & \multicolumn{2}{c|}{ Curso com mais de 200h (\%) } \\
\cline { 2 - 5 } & $\begin{array}{c}\text { Público } \\
\text { Urbano }\end{array}$ & Rural & $\begin{array}{c}\text { Público } \\
\text { Urbano }\end{array}$ & Rural \\
\hline Brasil & $\mathbf{4 5 , 4 2}$ & $\mathbf{6 7 , 8 4}$ & $\mathbf{4 1 , 2 8}$ & $\mathbf{1 4 , 3 9}$ \\
\hline Guatemala & 66,09 & 70,55 & 8,39 & 9,30 \\
\hline México & 54,83 & 70,33 & 3,24 & 0,0 \\
\hline Nicarágua & 48,28 & 67,95 & 13,79 & 7,38 \\
\hline Rep. Dominicana & 41,81 & 53,85 & 23,67 & 15,40 \\
\hline
\end{tabular}

Fonte: Dados retirados da Tabela 9 da pesquisa de Murillo e Martínez-Garrido (2015, p.255)

\footnotetext{
14 Palavra de origem inglesa, utilizada no âmbito empresarial, significando todas as partes ou organizações interessadas ou afetadas por atividades ou decisões de uma outra empresa. No caso da escola, os stakholderes são: os pais, comunidade em geral, professores, fornecedores, etc.
} 
O Brasil está em posição muito aquém do Paraguai, Colômbia e Perú. A necessidade de política pública voltada para tal fim é nítida e urgente, tendo em visto a relevância do cargo de diretor(a) da escola. Imaginemos, então, o contexto em que a Constituição determina como modelo de gestão, a "gestão democrática", sem ao menos definir os princípios democráticos. O que é uma "gestão democrática"? Está a serviço de que ou de quem?

A investigação efetuada por Fonseca (2018) evidencia que as escolas com os melhores resultados não apenas do IDEB, mas também na promoção do desenvolvimento geral do estudante, têm diretores com outra formação além da Licenciatura em Pedagogia. É possível que um dos fatores que contribui para a precariedade na formação do corpo diretivo esteja no currículo dos cursos, principalmente, as Licenciatura e/ou Bacharelado em Pedagogia, já que seu Parâmetro Curricular orienta uma formação de cunho geral, ficando a cargo de cada egresso complementar a sua formação para que ocupe o cargo de diretor(a) da escola, adquirindo competências específicas à gestão escolar. Também sugere que as escolas com os melhores resultados no IDEB, além do melhor clima organizacional para se trabalhar, estão diretamente ligadas à formação de seu corpo diretivo e o envolvimento dos professores no Projeto Pedagógico.

O papel da liderança juntamente com a equipe é fundamental para os resultados exitosos da escola. Hargreaves e Fullan (2012, p. 61) afirmam que o bom desempenho desse conjunto depende de cinco "Cs": "capacidade, compromisso, carreira, cultura e condições para o ensino".

Assim, podemos afirmar que, em qualquer realidade organizacional, devemos: ter em conta o caráter sistêmico das organizações; entender a realidade local em que a escola está inserida; procurar meios que atendam aos objetivos e especificidades da organização escolar.

Dessa forma, sem definição governamental clara e regulamentar sobre o que vem a ser "gestão democrática", como determinado pelo Art. 206 da Constituição; sem política pública nacional que ampare a formação e instrumentalize o corpo diretivo, a polissemia conceitual dificulta o cotidiano da gestão da escola no cumprimento de seus objetivos. 
Os entendimentos sobre "gestão democrática" são diversos e dão ao(à) diretor(a), uma delegação de poder ao qual não está preparado nem instrumentalizado para o exercício da função. Um espaço democrático se conquista com liderança intencionalmente educativa para tal. Não será apenas a escolha democrática (eleição) do(a) diretor(a) que fará da gestão, em um passe de mágica, "democrática".

Por fim, na próxima seção, explicaremos como a pesquisa vem sendo desenvolvida metodologicamente.

\section{Metodologia}

Segundo sua finalidade, a pesquisa tem por objetivo geral investigar como o conceito de "gestão democrática" é entendido nas escolas, e se exerce alguma influência no padrão de qualidade. Para tanto, o universo da pesquisa são o(a)s diretores(as) das escolas públicas que atendem o Ensino Médio, situadas no Estado da Bahia, Brasil. Assim, considerando seu objetivo, trata-se de uma pesquisa exploratória, segundo Gil (1999, p. 27), "a pesquisa exploratória tem como propósito proporcionar maior familiaridade com o problema, tendo em vista torná-lo mais explícito ou a construir hipóteses".

No tocante ao procedimento, trata-se de um estudo descritivo, pois "esse tipo de método assegura que o pesquisador procure conhecer e interpretar a realidade sem nela interferir para modificá-la" (Rudio, 1992, p. 55). Além disso, o autor afirma que tal tipo de pesquisa deve conter enfoques, os quais subsidiarão a interpretação dos dados.

A pesquisa percorre os seguintes procedimentos: no primeiro momento dedicamos a revisão de literatura. Aqui, fizemos um breve levantamento sobre o entendimento da "gestão democrática" na perspectiva de: Luck, 1996; Ozga, 2009; Libânio, 2001; Paro, 2007 e Lima, 2014. Também procedemos com leituras sobre padrão de qualidade, tomando por base as ideias de Ozga, 2009; Gadott, Barroso e Carvalho, 2011; Ravitch, 2011 e Monarca, 2018a, 2018b.

No segundo momento, o desenho para a realização deste estudo experimental inclui as seguintes etapas: a construção de um questionário constituído por cinco 
Blocos a saber: I) dados gerais; II) perfil do(a)s diretores(as); III) gestão da escola; IV) perfil da escola; e, no último, o V) identificar as competências prescritas e não prescritas do(a) diretor(a), ferramentas utilizadas na gestão, autoimagem, clima organizacional e a avaliação do IDEB.

No momento seguinte, o questionário foi enviado, eletronicamente, para os diretores das 823 escolas públicas do Ensino Médio do Estado da Bahia. Dos questionários enviados, obteve-se um retorno de 126 considerados válidos e são os que analisaremos como resultados preliminares da pesquisa. Desse modo, optou-se por visitar seis escolas considerando os critérios de notas do IDEB entre 4 e 5 são identificadas como as "melhores" escolas, e as de IDEB 1 a 3 consideradas como "inapropriadas" ou seja, aquelas que precisam de atenção, por parte do corpo diretivo, no sentido de melhorarem a aprendizagem de seus estudantes.

As entrevistas foram feitas obedecendo a uma estrutura de questões semiestruturadas. A pesquisa tem a intenção inicial de fazer um diagnóstico da situação das escolas públicas do Ensino Médio no Estado da Bahia com relação à sua qualidade. Nesta primeira abordagem, apresentaremos apenas um recorte da pesquisa no que concerne ao perfil do(a) diretor(a) e alguns aspectos sobre o cotidiano da "gestão democrática" da escola.

Para resguardarmos o anonimato dos sujeitos, designamo-nos, aqui, o(a)s diretores(as) das escolas com melhor IDEB como DM1, DM2 e DM3, e das escolas com IDEB inapropriado como DI1, DI2 e DI3.

\section{Resultados e Análise dos Dados: contextos encontrados}

A presente pesquisa se dá em razão de o Estado da Bahia, na avaliação do IDEB dos últimos 3 anos, apresentar um rendimento abaixo da meta nacional no Ensino Médio como pode ser observado no Quadro 2 a seguir:

Quadro 2. Resultados e metas do IDEB

\begin{tabular}{|c|c|c|c|c|c|c|c|c|}
\hline \multirow{3}{*}{ Nacional } & \multicolumn{3}{|c|}{ IDEB observado } & \multicolumn{6}{c|}{ Metas } \\
\cline { 2 - 9 } & $\mathbf{2 0 1 3}$ & $\mathbf{2 0 1 5}$ & $\mathbf{2 0 1 7}$ & $\mathbf{2 0 1 3}$ & $\mathbf{2 0 1 5}$ & $\mathbf{2 0 1 7}$ & $\mathbf{2 0 1 9} *$ & $\mathbf{2 0 2 1} *$ \\
\cline { 2 - 9 } & 3,7 & 3,7 & 3,8 & 3,9 & 4,3 & 4,7 & 5,0 & 5,2 \\
\hline Estadual & 3,4 & 3,5 & 3,5 & 3,6 & 3,9 & 4,4 & 4,6 & 4,9 \\
\hline
\end{tabular}

Fonte: Saeb/INEP - Censo Escolar dos anos. * Valores projetados 
Preocupados com a recuperação dos resultados da aprendizagem dos estudantes do Ensino Médio, no Estado da Bahia, o Grupo de Pesquisa em Educação e Gestão (GPEG), da Universidade Estadual de Santa Cruz (UESC), decidiu, com o apoio financeiro da própria Universidade, investigar qual o entendimento dos diretores sobre o conceito de "gestão democrática", e se ele oferece alguma contribuição para o padrão de qualidade da escola pública?

Assim, como explicitado na metodologia, preparamos um questionário online direcionado apenas aos(às) diretores(as) das escolas constituído de cinco Blocos a saber: I) dados gerais ; II) perfil do(a)s diretores(as); III) gestão da escola; IV) perfil da escola; e, no último, o V) identificar as competências prescritas e não prescritas do(a) diretor(a), ferramentas utilizadas na gestão, autoimagem, clima organizacional e a avaliação do IDEB.

Nesse recorte da pesquisa, utilizaremos informações extraídas das 126 respostas do questionário, apenas sobre algumas questões dos Blocos II, III e V, além das seis entrevistas presenciais com diretores(as) das escolas.

O Bloco I: dados gerais, deixamos de apresentá-los para preservar o anonimato das escolas, como também não ser o foco do artigo.

Assim, como resultado preliminar dos Blocos temos:

O Bloco II: Caracterização da amostra

Nesse Bloco, conforme se pode verificar no Gráfico 2, encontramos os seguintes resultados: com relação ao gênero, a maioria $(56,1 \%)$ é do gênero feminino. Já a idade, 48,8\%, está na faixa entre 41 a 50 anos. Essa faixa de idade nos indica que se trata de um profissional com um certo repertório de experiências consolidadas na área. Sobre o gênero, historicamente, a forte presença da mulher brasileira nas matrículas das Escolas Normal contribuiu para que, posteriormente, elas fossem presença majoritária como profissionais na educação brasileira. 


\section{Gráfico 2. Perfil do(a)s diretores(as)}

Qual a sua faixa de idade?

125 respostas

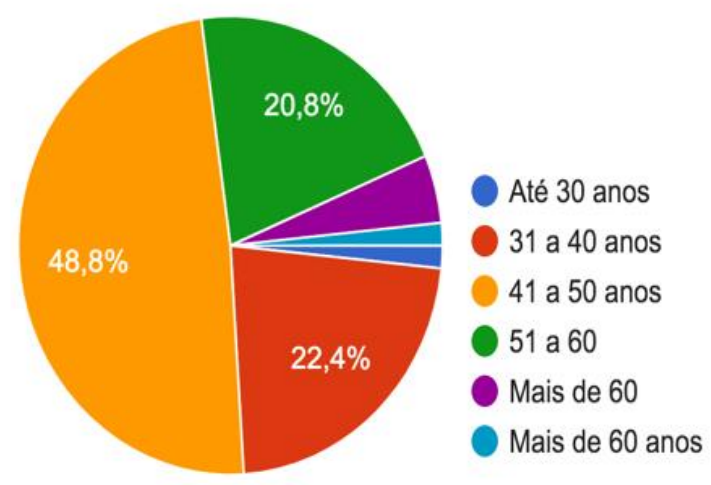

Gênero

123 respostas

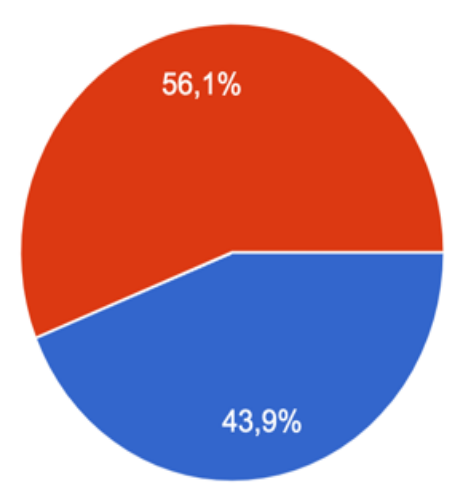

Masculino

Feminino

Fonte: Elaboração a partir dos dados da pesquisa.

Quando perguntado no questionário, sobre o nível de formação do(a) diretor(a) da escola, encontramos que 97,5\% têm algum curso de licenciatura, dentre eles, os de maior incidência por ordem de grandeza são: Letras, História e Matemática; um percentual pequeno $(11,7 \%)$ aparece com algum curso de bacharelado, dentre eles o de maior incidência é o curso de Pedagogia seguido pelo de Direito. Um alto percentual de diretores (80\%) afirma possuir algum curso de pós-graduação lato sensu e destes, menos de $20 \%(16,8 \%)$ fizeram curso na área de Gestão Escolar. O que significa que a maioria fez cursos ligado à sua formação inicial, ou seja, o de professor. Tanto que ao ser perguntado: o curso de graduação/licenciatura the preparou para ser gestor escolar? As respostas mostraram que $85 \%$ afirmaram que "não preparou ou preparou pouco".

Apesar de a maioria dos sujeitos desse recorte ter entre 40 e 50 anos, significa que fizeram seus cursos de Ensino Superior a partir dos anos 80 e, portanto, ainda sob a regência da Resolução n.0 2/1969 em que as habilitações (especializações) eram o foco dos cursos de Pedagogia. Isso nos impele a inferir, a partir da análise dos programas dos cursos, que esses estavam voltados mais à teoria do que às práticas do cotidiano da escola. Tanto que há depoimento de professor(a) (diretor/a) que declara: "A Universidade não proporciona experiência real sobre o assunto" 
(Diretor da Escola D26) ${ }^{15}$. O Diretor da Escola (D105) disse: "A graduação visa o preparo do percurso profissional sem a preocupação com a gestão escolar". "Porque o curso é específico para a atuação como professor", disse o D12.

Desse Bloco, podemos concluir que há alguma falha na questão curricular dos cursos de Pedagogia e Letras além de não haver investimento público nem pessoal para a formação complementar específica para a atuação da direção da escola. O(a) diretor(a) da escola é o profissional de maior protagonismo e, portanto, a sua formação é fator preponderante para que a escola cumpra com eficiência seus objetivos.

\section{O Bloco III: Gestão da escola}

1) Esse Bloco nos indica algumas contradições e dilemas sobre 0 entendimento dos sujeitos com relação a "gestão pedagógica", sua prática no cotidiano da escola e sua formação. Sobre o entendimento conceitual de "gestão democrática", perguntamos na questão 7: o que você entende por "gestão democrática" e se ela oferece alguma contribuição para a qualidade da escola? Posteriormente, 7.1. Já exerceu a função de gestor(a) escolar antes? 7.2. Como você considera a participação dos professores e Associação de Pais e Mestres no cotidiano da escola?

Para a questão 7 , obtivemos nas respostas de $93 \%$ dos respondentes dizendo com palavras diferentes, mas com o mesmo significado, que: gestão democrática "é a gestão com a participação da comunidade, a Associação de pais, alunos e professores". O restante dos respondentes (7\%) faz declarações evasivas e desconectadas com a pergunta, tais como: "depende do governo". "É difícil, as pessoas não gostam de participar e apenas criticam", etc.

As respostas dos $93 \%$ do(a)s diretores(as) corroboram com os entendimentos dos autores elencados no Quadro 2 como também a nossa hipótese inicial de que é entendido a "gestão democrática" como "escolha democrática" (eleição) do(a) diretor(a) e não o modelo de gestão, que deve ser o sentido de identificar a forma, o modelo ou estilo em que qualquer organização é

${ }^{15}$ Para garantir o anonimato das escolas, cada formulário respondido pelo(a) diretor(a) recebeu numeração de 001 a 823 que foi o número total de questionários enviados. 
dirigida; além de empregada para designar o sistema organizacional interno aplicado na monitoração das organizações, ou seja, a redação constitucional do referido artigo não é clara para o que se deseja.

No tocante a pergunta 7.1 , verificamos que $68,5 \%$ do(a)s diretores(as) estavam em seu primeiro mandato, enquanto que $31,5 \%$ estava na reeleição. Dos seis entrevistados, somente dois estavam na reeleição e um deles, o DM3, relatou que no segundo mandato: "faz o diretor ter mais segurança na 'gestão democrática' fica mais conhecido na sociedade, e os pais passam a ter mais confiança nele. Eu acho até que no segundo mandato os pais participam mais".

Já na pergunta 7.2, nesse item, as respostas apresentam posturas distintas no que tange as participações do(a)s diretores(as) em que as escolas têm o melhor IDEB e para as de IDEB inapropriado.

Com relação à participação, $87 \%$ dos questionários dão conta de que a participação é pequena.

\section{Análise dos resultados das entrevistas}

Já nas entrevistas, o(a)s diretores(as) das três escolas com resultados inapropriados responderam assim: o DI1: "faz falta uma política pública que prepare o diretor para a gestão da escola; as pessoas não querem participar; todo mundo (os pais) anda meio cansado do trabalho e deixa as decisões na mão da escola"; o DI2: "ninguém participa, falta tudo, não tem dinheiro para nada e o governo quer resultado"; o DI3: "querem tudo da gente. Veja aí professora, não temos computadores, a internet funciona quando quer... como o povo pode participar se o governo não faz a parte dele?"

Essas três escolas têm respectivamente IDEB: em 2013: 1,0; 2015: 1,3 e 2017: não constam informações disponíveis no INEP. Para finalizar, fizemos uma pergunta que não constava no questionário apenas para fechar nossas suposições. Perguntamos: qual o IDEB de sua escola? O(a)s três diretores(as) desconheciam a nota. É interessante observar que esses gestores têm posturas e concepções idênticas, são pessimistas com relação aos professores (pouco colaborativos), aos pais, apontando sempre as responsabilidades aos outros. 
Em contrapartida, as outras três escolas entrevistas que apresentam IDEB próximo a meta ou, até mesmo, superior seus(suas) diretores(as) apresentam postura também idênticas na direção contrária, são proativos no cargo de direção; têm mais de uma formação além da licenciatura (Direito e Administração); apresentam posição de liderança com o corpo docente e na comunidade, exigentes com relação à disciplina e suas estratégias na gestão e estão intimamente ligadas à meritocracia. 0 diretor da escola DM1 declarou:

[...] o resultado da qualidade da escola está intimamente ligado ao desempenho da equipe. Aqui, nós nos vemos como um time. Estudantes, professores e servidores, gostam da escola. Temos muitos estudantes que saem daqui e são aprovados de primeira em Universidades de relevância da Bahia e até de outros Estados. Primamos pela disciplina e respeito.

Na mesma direção, apresentam-se DM2 e DM3, que declaram os mesmos princípios de disciplina, de respeito e de compromisso, complementou o DM2:

[...] temos conhecimentos sobre elaboração de projetos e não fico esperando e dependendo apenas do governo, vou atrás de outras fontes. Construí aqui uma quadra de esportes com recursos de projetos. A escola tem que ser dinâmica e acompanhar a evolução das coisas. Se não fizer isso fica ela e os estudantes para traz.

Essas entrevistas nos fizeram repensar e ratificar numa frase várias vezes dita pelo prof. António Nóvoa: "na educação não é possível separar a dimensão da profissionalidade da dimensão da pessoalidade e isso implica em um compromisso pessoal, de valores, do ponto de vista da profissão".

A pesquisa documental apontou que, no Estado da Bahia, a indicação política do(a) diretor(a) da escola, no Ensino Médio, deixou de existir a partir de 2008, com o Decreto n. ${ }^{\circ} 11.218$, de 18 de setembro de 2008. Na primeira edição e nos demais Decretos n.os 13.202 de 19 de agosto de 2011, e 16.385 de 26 de outubro de 2015, é exigida dos candidatos ao cargo de diretor uma certificação de conhecimentos em gestão escolar, que consiste em uma prova simples; a Secretaria de Educação encaminha um programa. 
Para dirimir melhor a necessidade da formação específica do(a) diretor(a) da escola, perguntamos: para você, o que caracteriza um bom ou uma boa gestor(a)/diretor(a) escolar?

Para exemplificar essa questão elencamos uma fala do(a) diretor(a) de uma das escolas com melhor IDEB, o DM1 exprimiu que:

[...] um bom gestor tem planos bem definidos e objetivos claros. Ele planeja o seu trabalho e traça a participação de todos de forma igualitária e justa. Um verdadeiro líder deve ser proativo e está em constate procura de inovações e oportunidades pra fazer as coisas acontecerem.

É importante salientar que as seis entrevistas foram realizadas individualmente, com horário agendado e em suas respectivas escolas. Duas escolas em Salvador, Bahia, Brasil, uma em Ilhéus, uma em Camacan e duas em Itabuna. Esses três municípios pertencentes também ao Estado da Bahia, Brasil.

A segunda pergunta da questão de pesquisa é: se a "gestão democrática" oferece alguma contribuição para o padrão de qualidade das escolas? Aqui, a situação fica ainda mais complexa, uma vez que o conceito de qualidade, como define Monarca (2018), é simbólico. Se observarmos os PNE, constatamos que os técnicos que estipulam as metas e as estratégias não têm conhecimento das diferentes realidades regionais brasileira, por exemplo, a Meta 7: Fomentar a qualidade da educação básica em todas as suas etapas e modalidades, com melhoria do fluxo escolar e da aprendizagem de modo a atingir as seguintes médias nacionais para o IDEB no Ensino Médio:

\section{Quadro 3. Resultados e metas do IDEB}

\begin{tabular}{|l|c|c|c|c|}
\hline IDEB & 2015 & 2017 & $2019^{*}$ & $2021^{*}$ \\
\hline Ensino Médio & 4,3 & 4,7 & 5,0 & 5,2 \\
\hline
\end{tabular}

Fonte: Saeb/INEP - Censo Escolar dos anos. * Valores projetados

\section{Considerações Finais}

$\mathrm{O}(\mathrm{a})$ diretor(a) da escola é o profissional com maior protagonismo e relevância para conduzir a consecução dos objetivos da escola entre o grupo que a compõe. Ele desempenha papel importante no desenvolvimento da qualidade da educação. Para tanto, sua formação deve convergir para dar-lhe competências e 
habilidades sistematizadas nas áreas: gerencial, administrativa e pedagógica, sem contar com a competência de representação para os distintos fins da escola.

Esse pequeno recorte do projeto de pesquisa, Gestão da Escola e os Resultados do IDEB: qual a relação? Nos mostra que a escola ainda não encontrou um modelo de gestão apropriado a suas necessidades e peculiaridades nem o(a) gestor(a) está instrumentalizado(a) para tal fim. É certo que o estilo de gestão está intimamente ligado às características da pessoalidade do(a) diretor(a), mas não se pode esperar apenas por isso, mesmo porque as características da pessoalidade não são itens da seleção para o exercício do cargo.

A literatura mostra Ravitch (2011) experiências de insucesso no modelo americano quando se deseja adotar a estrutura, estritamente, empresarial para a escola, visto que ela possui características próprias e seus profissionais precisam estar preparados para tal fim.

Os resultados desta pesquisa nos dão fortes indícios, embora com uma amostra preliminar e ainda pequena, que faltam políticas públicas voltadas à capacitação do(a)s diretores(as), e o reconhecimento da capacitação profissional continuada como condição para se atingir mudanças eficientes no cotidiano da gestão da escola.

Assim, esperamos que a conclusão desta pesquisa, ainda aguardando respostas de quase 700 questionários, que deem suporte para novos estudos e subsidiem melhor a sistematização do conhecimento específico sobre a gestão da escola de modo a instrumentalizar o(a)s diretores(as), tornando-os(as) mais eficientes e com resultados que se reflitam no ensino-aprendizagem dos estudantes e, consequentemente, a melhoria das escolas públicas.

\section{Referências bibliográficas}

Aranha, M. L. (1996). História da Educação (2a ed.). São Paulo: Moderna.

Constituição da República Federativa do Brasil. (1998). Brasília, DF: Senado Federal. Disponível em https://bit.ly/2sFJy0a 
Fernandes, R. (2007). Índice de Desenvolvimento da Educação Básica (IDEB). Série Documental. Textos para discussão. Brasília: Instituto Nacional de Estudos e Pesquisas Educacionais Anísio Teixeira.

Fernández-González, N. (2019). El cercamiento neoliberal de la escuela pública en Madrid. Un estudio del discurso y la gubernamentalidad. Tesis doctoral inédita. Madrid: Universidad Autónoma de Madrid.

Fernández-González, N. y Monarca, H. (2018). Política educativa y discursos sobre calidad: usos y resignificaciones en el caso español. En H. Monarca (Coord.), Calidad de la Educación en Iberoamérica: Discursos, políticas y prácticas (pp. 1244). Madrid: Dykinson. Madrid: Dykinson. Disponível em https://bit.ly/2ug4sDM Fonseca, Sônia (2018). Gestão de Organizações de Ensino: uma perspectiva pedagógica. Curitiba: Appris.

Fundo Nacional de Desenvolvimento da Educação (s/n): Programa Dinheiro Direto na Escola (PDEE). Disponível em https://bit.ly/2v5TGAc

Freire, P. (1996). Pedagogia da Autonomia. Rio de Janeiro: Paz e Terra.

Gil, A. C. (1999). Métodos e técnicas de pesquisa social (5a ed.). São Paulo: Atlas. Hargreaves, A. e Fullan, M. (2012). Professional capital. Transforming teaching in every school. New York: Teachers College Press.

Harvey, D. (2008). O neoliberalismo história e implicações. São Paulo: Edições Loyola. Hora, D. L. (2006). Democracia, educação e gestão educacional na sociedade brasileira contemporânea. EccoS - Revista Científica, 8(1), 65-87.

Instituto Nacional de Estudos e Pesquisas Educacionais Anísio Teixeira (2016). Relatório do 10 ciclo de monitoramento das metas do PNE: biênio 2014-2016. Brasília, DF: INEP.

Lei n. 5.540/1968. Fixa normas de organização e funcionamento do ensino superior e sua articulação com a escola média, e dá outras providências. Disponível em http://www.planalto.gov.br/ccivil 03/leis/L5540.htm

Lei n. 9.394/1996, de 20 de dezembro de 1996. Estabelece as Diretrizes e Bases da Educação Nacional. Diário Oficial da União, Brasília, DF. Disponível em http://www.planalto.gov.br/ccivil 03/leis/19394.htm 
Lei n. 10.172/2001. Normatiza o Plano Nacional de Educação. Brasília, DF. Disponível em https://bit.ly/38w7iDt

Libânio, J. C. (2007). Concepciones y prácticas de organización y gestión de la escuela: consideraciones introductorias para un examen crítico de la discusión actual en Brasil. Revista Española de Educación Comparada, 13, 155-191.

Lima, L. A. (2014). Gestão democrática das escolas: do autogoverno à ascensão de uma Pós - Democracia Gestionária? Disponível em https://bit.ly/2G7MzJQ

Lück, H., Freitas, K., Girling, R. e Keith, S. (1996). A escola participativa o trabalho do gestor escolar. Rio de Janeiro: DP \& A.

Monarca, H. (Coord.) (2018a). Calidad de la Educación en Iberoamérica: Discursos, políticas y prácticas. Madrid: Dykinson. Disponível em https://bit.ly/2ug4sDM

Monarca, H. (2018b). Presentación: sobre calidad y sentidos en educación. En H. Monarca (Coord.), Calidad de la educación en Iberoamérica: Discursos, políticas y prácticas (pp. 5-11). Madrid: Dykinson. Disponível em https://bit.ly/38leORk

Murillo, F. J. e Martínez-Garrido, C. (2015). La formación de directores y directoras, un factor (Más) de inequidad escolar en América Latina. Revista Iberoamericana de Educación, 69, 241-266.

Ometto, A. M. H., Furtuoso, M. C. e Silva, M. V. da. (1995). Economia brasileira na década de oitenta e seus reflexos nas condições de vida da população. Revista de Saúde Pública, 29(5), 403-414.

Ozga, J. (2009). Governing education through data in England: From regulation to self-evaluation. Journal of education policy, 24(2), 149-162.

Paro, V. H. (2000). Gestão Democrática na Escola Pública (3a ed.). São Paulo: Ática.

Pereira, B. (1999). Reflexões sobre a Reforma Gerencial Brasileira de 1995. São Paulo: Revista do Serviço Público, 50(4), 5-29.

Ravitch, D. (2011). The death and life of the great American school system: how testing and choice are undermining education. Basic Books.

Resolução n. 2. Define as Diretrizes Curriculares Nacionais para a formação inicial em nível superior (cursos de licenciatura, cursos de formação pedagógica para graduados 
e cursos de segunda licenciatura) e para a formação continuada. Ministério da Educação/Conselho Federal de Educação. Disponível em https://bit.ly/2TMCw50 Rudio, F. V. (1992). Introdução ao Projeto de Pesquisa Científica. Petrópolis: Vozes. 